\title{
Corrosion Resistance of Silane-Modified Hydroxyapatite Films on Degradable Magnesium Alloys
}

\author{
Yan-Bin Zhao $^{1,2} \cdot$ Li-Qian Shi $^{1,2} \cdot$ Lan-Yue Cui $^{1,2} \cdot$ Chang-Lei Zhang ${ }^{1,2} \cdot$ Shuo-Qi Li ${ }^{1,2} \cdot$ Rong-Chang Zeng $^{1,2}$ • \\ Fen Zhang ${ }^{1,2} \cdot$ Zhen-Lin Wang $^{3}$
}

Received: 1 March 2017/Revised: 15 April 2017/Published online: 7 June 2017

(c) The Chinese Society for Metals and Springer-Verlag Berlin Heidelberg 2017

\begin{abstract}
A polymethyltrimethoxysilane (PMTMS)/hydroxyapatite (HA) hybrid coating was successfully fabricated on a magnesium alloy by hydrothermal treatment and immersion method. The microstructure and composition of the coating were characterized by using X-ray diffraction, Fourier transform infrared spectroscopy and scanning electron microscopy. The physical properties were investigated using scratch testing. At the same time, the corrosion resistance was evaluated via electrochemical and immersion tests. The results demonstrated that the corrosion resistance of the silane hybrid coating was significantly enhanced compared with the naked magnesium alloy. Especially, the corrosion current density of the PMTMS/HA magnesium alloy was three orders of magnitude lower than that of the bare material.
\end{abstract}

KEY WORDS: Magnesium alloys; Silane; Hydroxyapatite; Corrosion resistance; Biomaterial

\section{Introduction}

Owing to their safe degradation, great biocompatibility and excellent mechanical properties, magnesium and its alloys have attracted more and more attention and research in the field of biomaterials [1]. However, low corrosion

Available online at http://link.springer.com/journal/40195.

Shuo-Qi Li

lishuoqi@sdust.edu.cn

Rong-Chang Zeng

rczeng@foxmail.com

1 College of Materials Science and Engineering, Shandong University of Science and Technology, Qingdao 266590, China

2 State Key Laboratory of Mining Disaster Prevention and Control Co-Founded by Shandong Province and the Ministry of Science and Technology, Shandong University of Science and Technology, Qingdao 266590, China

3 College of Materials Science and Engineering, Chongqing University of Technology, Chongqing 400065, China resistance, as an inevitable response, poses a limit to the potential applications of magnesium alloys [2].

Surface modification, which is the most popular method on account of its low cost, simplicity and superior performance, is widely employed to improve the corrosion resistance of magnesium alloys, including hydrotalcite coating, chemical conversion coating, micro-arc oxidation (MAO) and plasma electrolytic oxidation (PEO) [3-6]. Especially, the Ca-P coating, such as hydroxyapatite (HA), has been extensively investigated and proved to have the excellent biocompatibility due to its porous microstructure [7]. However, it cannot provide a long-term protection because of the structure. As a result, this coating should be combined with micro-arc oxidation, sol-gel method or hydrothermal treatment, to reduce its in vitro and in vivo corrosion [8, 9].

Among these, we highlight the use of hybrid films formed by the reaction of hydrolysis and condensation of silanes. It has been confirmed that the silane hybrid films are efficient for the protection of metallic substrates against corrosion [10]. Within the common sol-gel processing, the alkoxide precursor with the alkyl group can be hydrolyzed and subsequently condensed via alcohol or water condensation [11]. The 
advantages of silane films are the low viscosity and the ability to form $\mathrm{Si}-\mathrm{O}-\mathrm{Si}$ bonds, allowing the oligomers to be transported easily and penetrate to a certain depth in order to obtain coatings without cracks [12]. At the same time, the formation of the silane structure can be intended to increase the coating thickness [13]. The resulting hybrid coating can protect metals against corrosion and also provide functional moieties that enable further attachment of bioactive molecules to enhance the interfacial interaction of metal implants with surrounding cells and tissue [14]. However, there are few studies on applying silanes to HA coating for magnesium alloys.

The objective of this work is to deposit the silane-HA hybrid coating on $\mathrm{Mg}$ alloys by cross-linking method and hydrothermal treatment $[15,16]$. This study could provide a valuable insight for predicting the HA-coated $\mathrm{Mg}$ alloy in vivo behavior.

\section{Experimental}

\subsection{Materials and Samples Pretreatment}

The substrates used in our experiment were as-extruded AZ31 magnesium alloys with nominal chemical composition (wt\%): Al 2.5-3.0, $\mathrm{Zn} \mathrm{0.7-1.3,} \mathrm{Mn}>0.20$, balance $\mathrm{Mg}$, supplied by Beijing Guangling Jinghua Science \& Technology Co., Ltd. These substrates were cut into squares with dimensions of $20 \mathrm{~mm} \times 20 \mathrm{~mm} \times 5 \mathrm{~mm}$, ground with 150/400/800/1500 grit SiC sandpapers, washed with a solution of deionized (DI) water and alcohol and dried by warm air. $\mathrm{KH}_{2} \mathrm{PO}_{4} \quad\left(\mathrm{M}_{\mathrm{w}}=228.22, \geq 99 \%\right)$ EDTA-Ca $\left(\mathrm{M}_{\mathrm{w}}=374.27,97 \%\right)$ and MTMS $\left(\mathrm{M}_{\mathrm{w}}=136.22,99 \%\right)$ were purchased from Qingdao Jingke Chemical Reagent Co., Ltd.

\subsection{Preparation of the Polymethyltrimethoxysilane (PMTMS)/Hydroxyapatite (HA) Coating}

The preparation process is schematically illustrated in Fig. 1. The HA coating was prepared via hydrothermal treatment [17]. EDTA-Ca and $\mathrm{KH}_{2} \mathrm{PO}_{4}$ with a $\mathrm{Ca} / \mathrm{P}$ molar ratio of 1.67:1 were dissolved into the DI water to obtain solution A. Solution B was prepared by normally stirring and adjusting the $\mathrm{pH}$ value for 8.9 with $1 \mathrm{~mol} / \mathrm{L} \mathrm{NaOH}$ solution. Then, this solution was transferred into a Teflonlined autoclave to immerse the pretreated magnesium alloys. Afterward, the autoclave was heated at $363 \mathrm{~K}$ for $360 \mathrm{~min}$. The as-prepared samples were rinsed with DI water and dried with warm air. The HA coating was obtained through the above steps. Then, the alloy samples were dipped into the MTMS solution ( $V_{\mathrm{MTMS}} / V_{\text {ethanol }} /$ $V_{\text {DI water }}=3: 10: 20$ ) at $50{ }^{\circ} \mathrm{C}$ for $2 \mathrm{~h}$. After aging at $393 \mathrm{~K}$ for $2 \mathrm{~h}$, the PMTMS/HA coating was constructed.

\subsection{Surface Characterization}

The surface and cross-section morphologies of the samples were identified via field-emission scanning electron microscopy (FE-SEM, Nova Nano SEM 450, USA) equipped with energy-dispersive X-ray spectroscopy (EDS) [18]. The phase composition of the samples was analyzed with X-ray diffraction (XRD, Rigaku D/MAX 2500 PC, Japan), with a $\mathrm{Cu}$ target at a scanning rate of $8 \% \mathrm{~min}$ [19]. The diffraction patterns were obtained between $10^{\circ}$ and $80^{\circ}$. The possible chemical bonding formed in the samples was confirmed via Fourier transform infrared spectroscopy (FTIR, Nicolet 380, Thermo electron, USA) [20].

\subsection{Corrosion Tests}

The corrosion resistance of the samples was evaluated by potentiodynamic polarization curves and electrochemical impedance spectra (EIS), which were obtained via an electrochemical analyzer (PAR Model 2273, Princeton, USA) [21]. The cell setup was a three-electrode system in which the samples were used as the working electrode, while a saturated calomel electrode and a platinum sheet were used as the reference and the counter electrodes, respectively. The polarization curves started from -2 to $-1 \mathrm{~V}$ at a scan rate of $1 \mathrm{mV} / \mathrm{s}$. The EIS studies were carried out at open-circuit potential for $10 \mathrm{mV}$ sinusoidal amplitude over a frequency range from $100 \mathrm{kHz}$ to $10^{-2} \mathrm{~Hz}$. These experiments were performed in Hank's balanced salt solution (HBSS): $8.0 \mathrm{~g} / \mathrm{L} \mathrm{NaCl}, 0.4 \mathrm{~g} / \mathrm{L} \mathrm{KCl}$, $0.14 \mathrm{~g} / \mathrm{L} \mathrm{CaCl}_{2}, 0.1 \mathrm{~g} / \mathrm{L} \mathrm{MgCl}_{2} \cdot 6 \mathrm{H}_{2} \mathrm{O}, 0.35 \mathrm{~g} / \mathrm{L} \mathrm{NaHCO}_{3}$, $1.0 \mathrm{~g} / \mathrm{L} \mathrm{C}_{6} \mathrm{H}_{6} \mathrm{O}_{6}$ (glucose), $0.06 \mathrm{~g} / \mathrm{L} \mathrm{MgSO}_{4} \cdot 7 \mathrm{H}_{2} \mathrm{O}, 0.06 \mathrm{~g} /$ $\mathrm{L} \mathrm{KH}_{2} \mathrm{PO}_{4}$ and $0.06 \mathrm{~g} / \mathrm{L} \mathrm{Na} \mathrm{HPO}_{4} \cdot 12 \mathrm{H}_{2} \mathrm{O}$.

Usually, polarization resistance $\left(R_{\mathrm{p}}\right)$, which is inversely proportional to the corrosion rate, can be calculated using the simplified Stern-Geary equation: $R_{\mathrm{p}}=\left(b_{\mathrm{a}} b_{\mathrm{c}}\right) /$ $\left[2.303 I_{\text {corr }}\left(b_{\mathrm{a}}+b_{\mathrm{c}}\right)\right]$, where $b_{\mathrm{a}}$ and $b_{\mathrm{c}}$ represent the Tafel slopes of the anode and cathode, respectively, while $I_{\text {corr }}$ is the corrosion current density.

The hydrogen evolution setup design was investigated by placing the samples under an inverted funnel in HBSS at $37.5 \pm 0.1{ }^{\circ} \mathrm{C}$, which was connected to a graduated burette. The water level in the burette was intermittently recorded during the immersion for $150 \mathrm{~h}$ with full surface exposure. Finally, the samples were taken out and dried by warm air for further characterization after the experiment.

\subsection{Scratch Testing}

The bonding force between the coating and the matrix could be characterized by MML Nanotest system (Micro Materials, Ltd.) with Rockwell diamond probe (its tip diameter was $25 \mu \mathrm{m})$. The nanoscratch tests were carried 

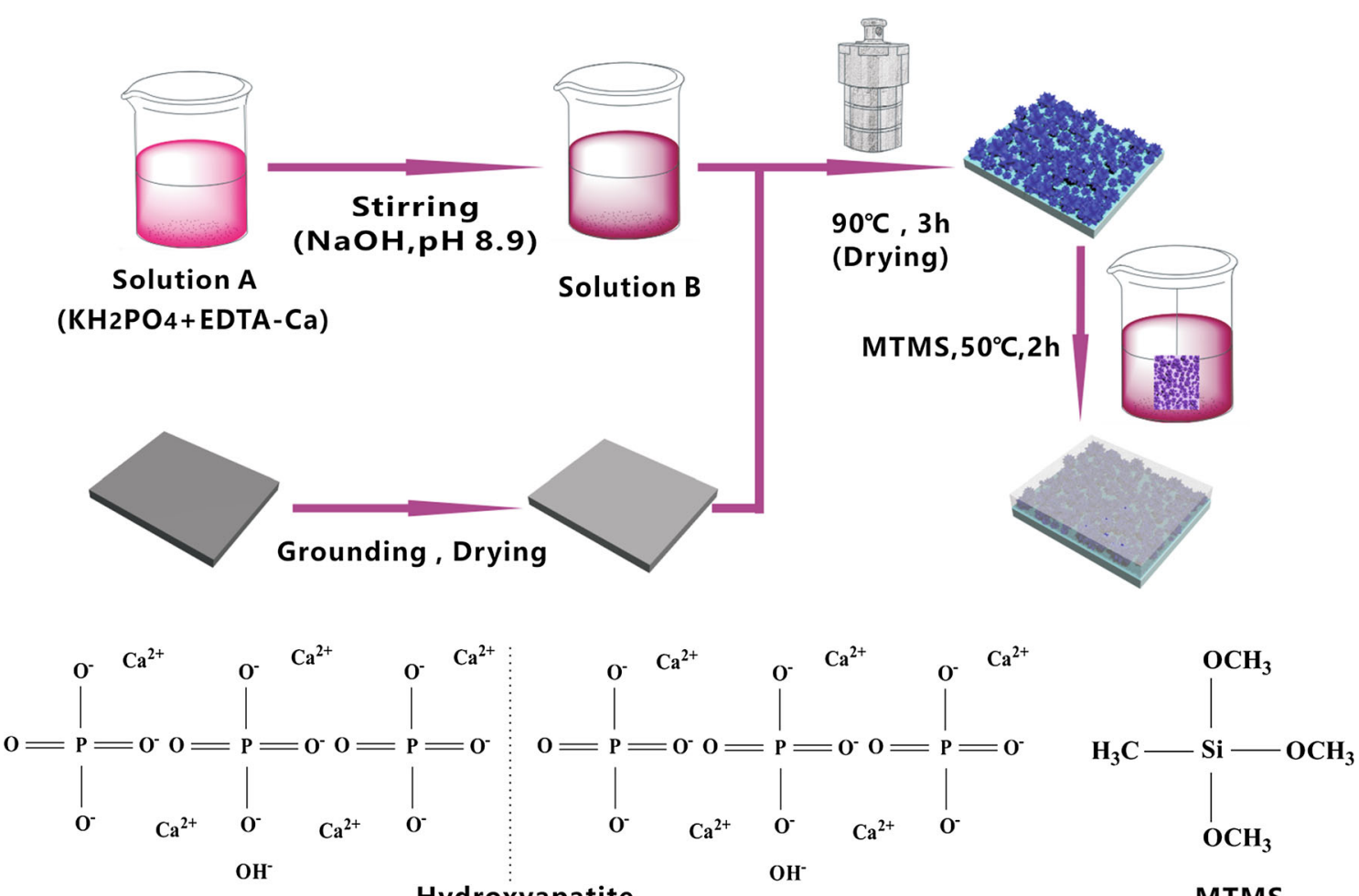

Hydroxyapatite

MTMS

Fig. 1 Schematic representation of the preparation of PMTMS/HA coating

out with the scan velocity of $2 \mathrm{~mm} / \mathrm{min}$ by linearly increasing the load to $10 \mathrm{~N}$, until the total scratch length reached $2 \mathrm{~mm}$. The tests were repeated for three times. The scratch images were captured by using an in situ optical microscope system in order to locate initial failure of the coating.

\section{Results}

\subsection{Composition and Surface Characterization of the Films}

The XRD spectra of AZ31, HA and PMTMS/HA films are shown in Fig. 2. Peaks corresponding to $\mathrm{Ca}_{10}\left(\mathrm{PO}_{4}\right)_{6}(\mathrm{OH})_{2}$ appeared in the spectra of both PMTMS/HA/AZ31 and HA/AZ31 [22-24]. For the PMTMS/HA coating, a weak diffraction peak of silane was detected at $22^{\circ}$, which demonstrated that the hybrid coating was prepared successfully [25, 26]. Thus, the XRD analysis provided clear evidence that the hydroxyapatite coating and the silane film were successfully prepared onto the surface of the magnesium alloys.

The FTIR spectra provide a qualitative analysis about organic groups in the coating as shown in Fig. 3. Firstly, the spectrum of HA/AZ31 in Fig. 3a presented an absorption peak of $\mathrm{O}-\mathrm{H}^{-}$at $3470 \mathrm{~cm}^{-1}$ [27]. The intense

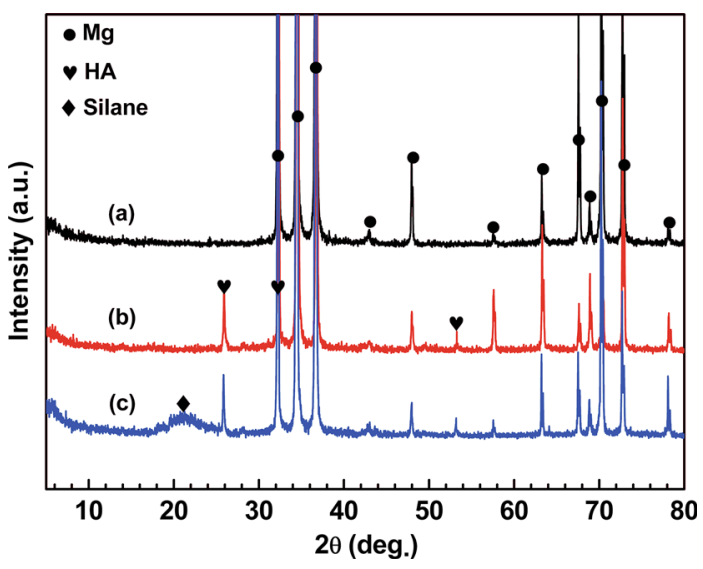

Fig. 2 XRD patterns of the AZ31 substrate $a$, the HA $b$ and the PMTMS/HA $c$ films

band at $1041 \mathrm{~cm}^{-1}$ showed the stretching modes of $\mathrm{PO}_{4}{ }^{3-}$, while the bands at 608 and $563 \mathrm{~cm}^{-1}$ were both the bending modes of $\mathrm{PO}_{4}{ }^{3-}$. Moreover, the adsorption bands at 876 and $1450 \mathrm{~cm}^{-1}$ are both due to the $\mathrm{CO}_{3}{ }^{2-}$ groups. A reliable explanation for these peaks is that small portions of the $\mathrm{PO}_{4}{ }^{3-}$ groups were substituted by the $\mathrm{CO}_{3}{ }^{2-}$ [28]. Secondly, in Fig. 3b, the spectrum of the PMTMS/HA/ AZ31, which presented absorption peaks at 1268 and $775 \mathrm{~cm}^{-1}$, corresponds to the $\mathrm{Si}-\mathrm{C}$ groups, while the presence of $\mathrm{C}-\mathrm{H}$ stretching vibrations was supported by the peaks at $2980 \mathrm{~cm}^{-1}$ [29]. The absorption peaks at 


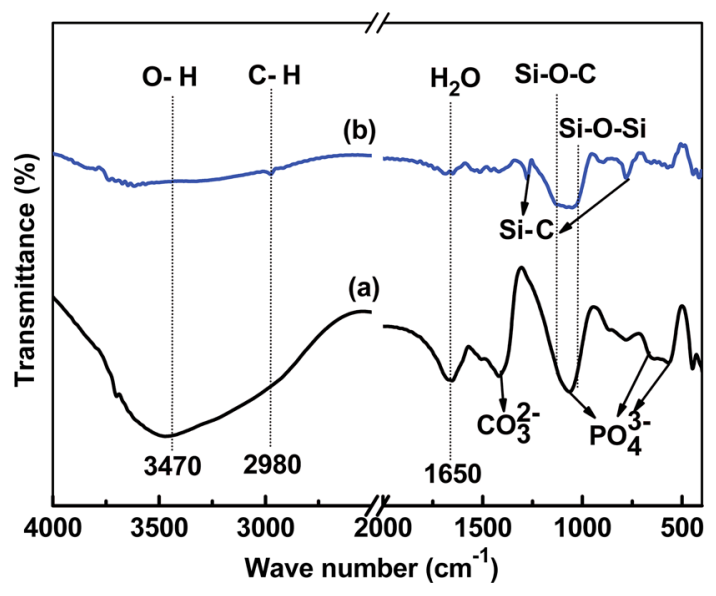

Fig. 3 FTIR patterns of the HA $a$ and the PMTMS/HA $b$ films

$1120 \mathrm{~cm}^{-1}$ were attributed to an asymmetric $\mathrm{Si}-\mathrm{O}-\mathrm{C}$ stretching band, and the peak at $1030 \mathrm{~cm}^{-1}$ was assigned to the $\mathrm{Si}-\mathrm{O}-\mathrm{Si}$ [30]. Therefore, the FTIR spectra clearly indicated that the PMTMS/HA coating was successfully synthesized with silane and hydroxyapatite.

Figure 4 illustrates the SEM morphology and the corresponding EDS spectra of HA and PMTMS/HA films. For the HA coating, it was found that the plate-shaped grains were accumulated on the surface of magnesium alloys and some grains were stacked to form the flower-like structure. The EDS spectrum of point A shows that the corrosion products are mainly composed of Ca (11.76\%), P (9.42\%), $\mathrm{O}$ and C. Compared with the SEM morphology of the HA film, the PMTMS/HA coating was more smooth, uniform and dense, except for some clusters due to the self-condensation of silane. The EDS analysis showed that the approximate chemical composition of the composite coating was $\mathrm{C}(29.88 \%)$, O (48.92\%) and Si $(21.20 \%)$. Consequently, the silane hybrid coating could well cover the bare magnesium alloy, providing an effective and longterm barrier.

The cross-sectional microstructure and the elemental mapping results are shown in Fig. 5. The thickness of the PMTMS/HA coating was approximately $2.7 \mu \mathrm{m}$, while the distribution of $\mathrm{Ca}, \mathrm{P}, \mathrm{Si}$ and $\mathrm{O}$ in the hybrid film was unified, uniform and denser. The results also indicated that the silane completely filled the porous structure of the hydroxyapatite.

\subsection{Electrochemical Corrosion Test}

The potentiodynamic polarization curves (Tafel) are applied to investigate the anti-corrosion properties of samples in Fig. 6, and the corresponding results calculated by extrapolation based on the polarization plots are summarized in Table 1. The $I_{\text {corr }}$ values for bare AZ31, HA coating and PMTMS/HA coating were equal to $1.84 \times 10^{-5}$, $1.77 \times 10^{-6}$ and $3.86 \times 10^{-8} \mathrm{~A} / \mathrm{cm}^{2}$, respectively. The $I_{\text {corr }}$ value of the silane hybrid HA film was approximately $2.18 \%$ of that of the HA film and $0.21 \%$ of that of the AZ31. The list of the values of $R_{\mathrm{p}}$ in the descending order is: PMTMS/HA coating $\left(3.87 \times 10^{6} \Omega \mathrm{cm}^{2}\right)>$ HA coating $\left(3.94 \times 10^{4}-\right.$ $\left.\Omega \mathrm{cm}^{2}\right)>$ the AZ31 substrate $\left(3.76 \times 10^{3} \Omega \mathrm{cm}^{2}\right)$. Thus, the silane hybrid coating exhibited clearly an excellent corrosion protection for the AZ31 magnesium alloy.

EIS was involved to investigate the corrosion behavior of samples, and the corresponding results are shown in Fig. 7a-c. Firstly, the diameters (two capacitive loops) of
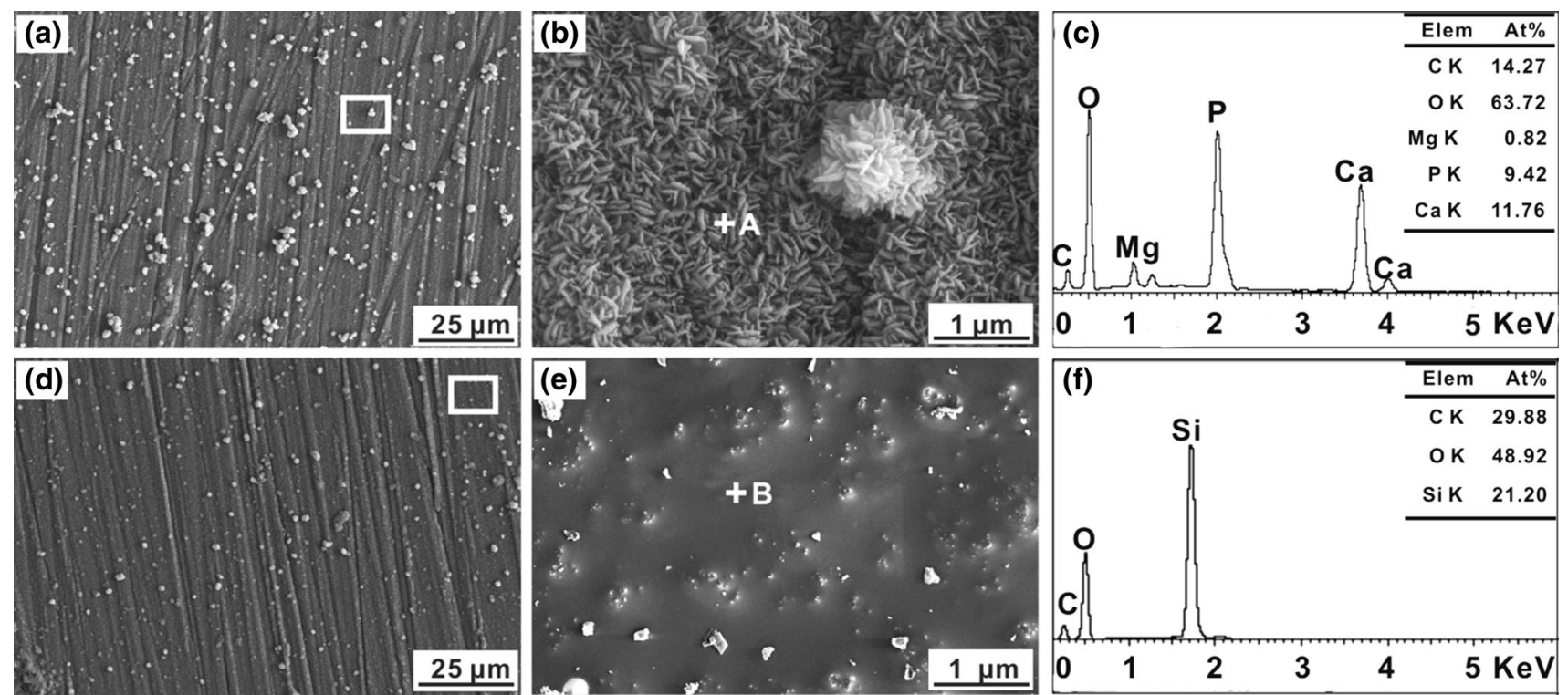

Fig. 4 Surface morphologies and the corresponding EDS spectra of the HA a, b, $\mathbf{c}$ and the PMTMS/HA films d, e, $\mathbf{f}$ 

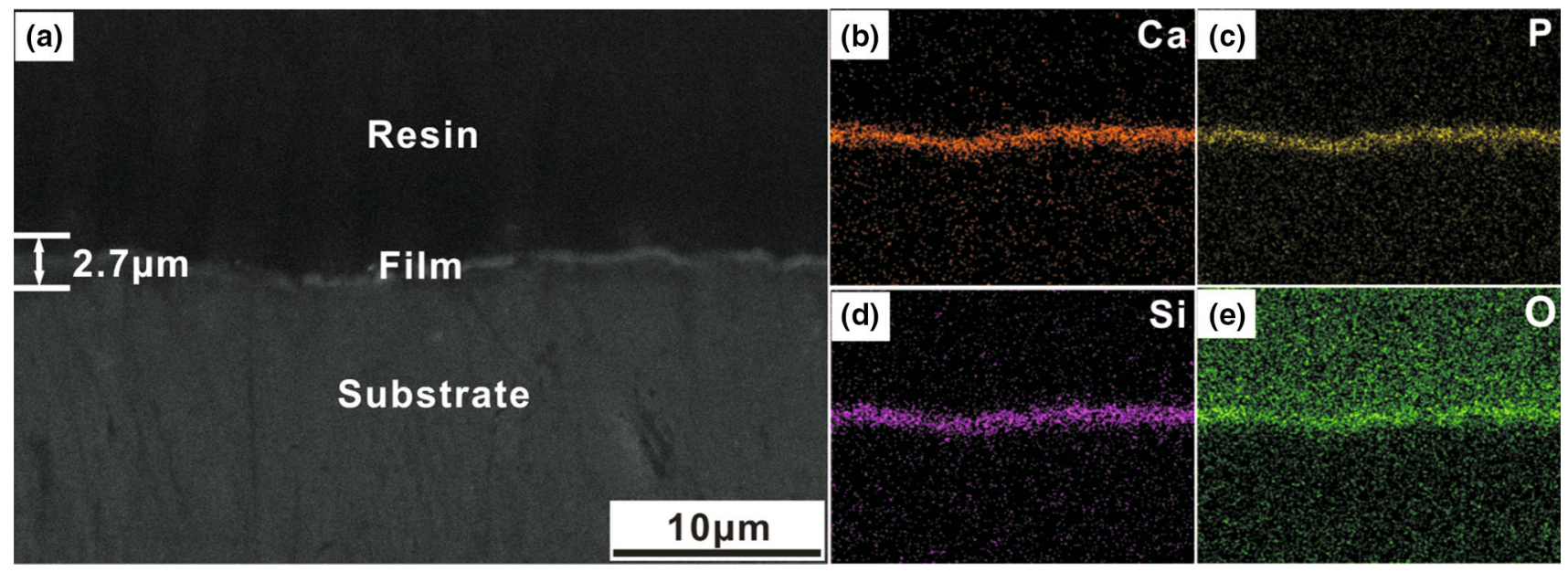

Fig. 5 Cross-sectional morphology a and the elemental mapping results b, c, d, e of PMTMS/HA film

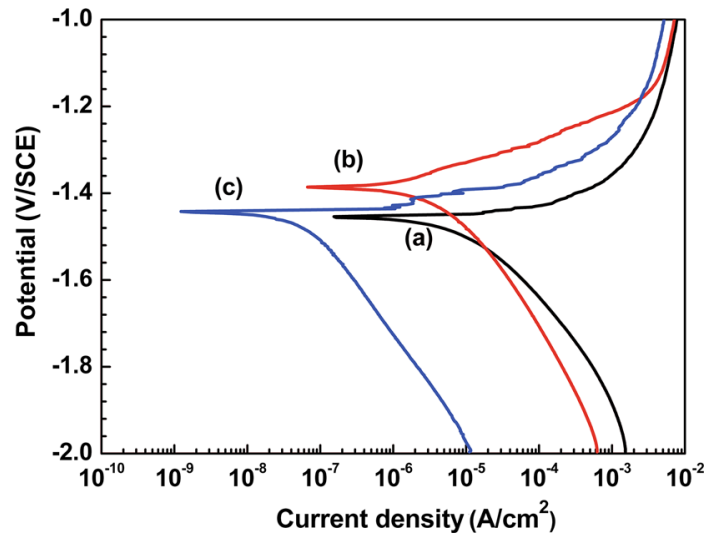

Fig. 6 Polarization curves of the AZ31 $a$, the HA coating $b$ and the PMTMS/HA coating $c$

the PMTMS/HA/AZ31 are the largest among the three samples in Fig. 7a. Secondly, the silane hybrid HA film had the highest value of IZl. Thirdly, in Fig. 7c, the phase angle of curve iii is loftier and wider, revealing that the hybrid film was uniform and denser. Therefore, these evidences indicate that the PMTMS/HA coating superiorly enhanced the corrosion resistance of the magnesium alloy.

In order to better understand the mechanism of the corrosion behavior in HBSS, the equivalent electrical circuit (EEC) for EIS plots was applied to fit the experimental data via ZSimpWin software. Figure $7 \mathrm{~d}-\mathrm{f}$ shows the EECs of the AZ31 substrate, the HA film and the PMTMS/HA film, respectively. In these equivalent circuits, $R_{\mathrm{s}}$ was the solution resistance between the reference electrode and the working electrode, $R_{\mathrm{ct}}$ denoted the charge transfer resistance, and $R_{\mathrm{c}}$ represented the coating resistance (virtual pore resistance) paralleled with a constant phase element $\left(\mathrm{CPE}, Y_{\mathrm{CPE}}(\omega)=1 / Z_{\mathrm{CPE}}=Q_{\mathrm{a}}(\mathrm{j} \omega)^{n}\right)$. Based on the proposed equivalent circuit models and the properties of the composite coating, the EIS curves were best fitted and the corresponding values of the equivalent circuit parameters are listed in Table 2. As it is well known, higher $R_{\mathrm{ct}}$ values represent lower dissolution rates [31]. The low $R_{\mathrm{ct}}$ value of the AZ31 substrate $\left(855 \Omega \mathrm{cm}^{2}\right)$ suggests a high corrosion rate. Conversely, the increased $R_{\mathrm{ct}}$ value of the HA/AZ31 $\left(2826 \Omega \mathrm{cm}^{2}\right)$ emphasizes the beneficial effect of the hydroxyapatite film. Moreover, the large $R_{\mathrm{ct}}$ value of the PMTMS/HA film $\left(7108 \Omega \mathrm{cm}^{2}\right)$ demonstrates that the composite coating clearly enhances the corrosion resistance of the magnesium alloy.

\subsection{Immersion Tests}

The corrosion rate during immersion can be determined via hydrogen monitoring, which is performed by the drainage gas collecting method [32]. The hydrogen evolution rates (HERs) of AZ31 substrate, HA coating and PMTMS/HA coating in HBSS are shown in Fig. 8. The HERs of the tested samples could be ranked in the increasing order as

Table 1 Electrochemical parameters of the polarization curves in HBSS

\begin{tabular}{lllcrl}
\hline Sample & $E_{\text {corr }}(\mathrm{V} / \mathrm{SCE})$ & $I_{\text {corr }}\left(\mathrm{A} / \mathrm{cm}^{2}\right)$ & $B_{\mathrm{a}}(\mathrm{mV} /$ decade $)$ & $-b_{\mathrm{c}}(\mathrm{mV} / \mathrm{decade})$ & $R_{\mathrm{p}}\left(\Omega \mathrm{cm}^{2}\right)$ \\
\hline AZ31 & -1.47 & $1.84 \times 10^{-5}$ & 94.31 & 231.54 & $3.76 \times 10^{3}$ \\
HA/AZ31 & -1.39 & $1.77 \times 10^{-6}$ & 92.62 & 218.65 & $3.94 \times 10^{4}$ \\
PMTMS/HA/AZ31 & -1.45 & $3.86 \times 10^{-8}$ & 146.83 & 256.32 & $3.87 \times 10^{6}$ \\
\hline
\end{tabular}



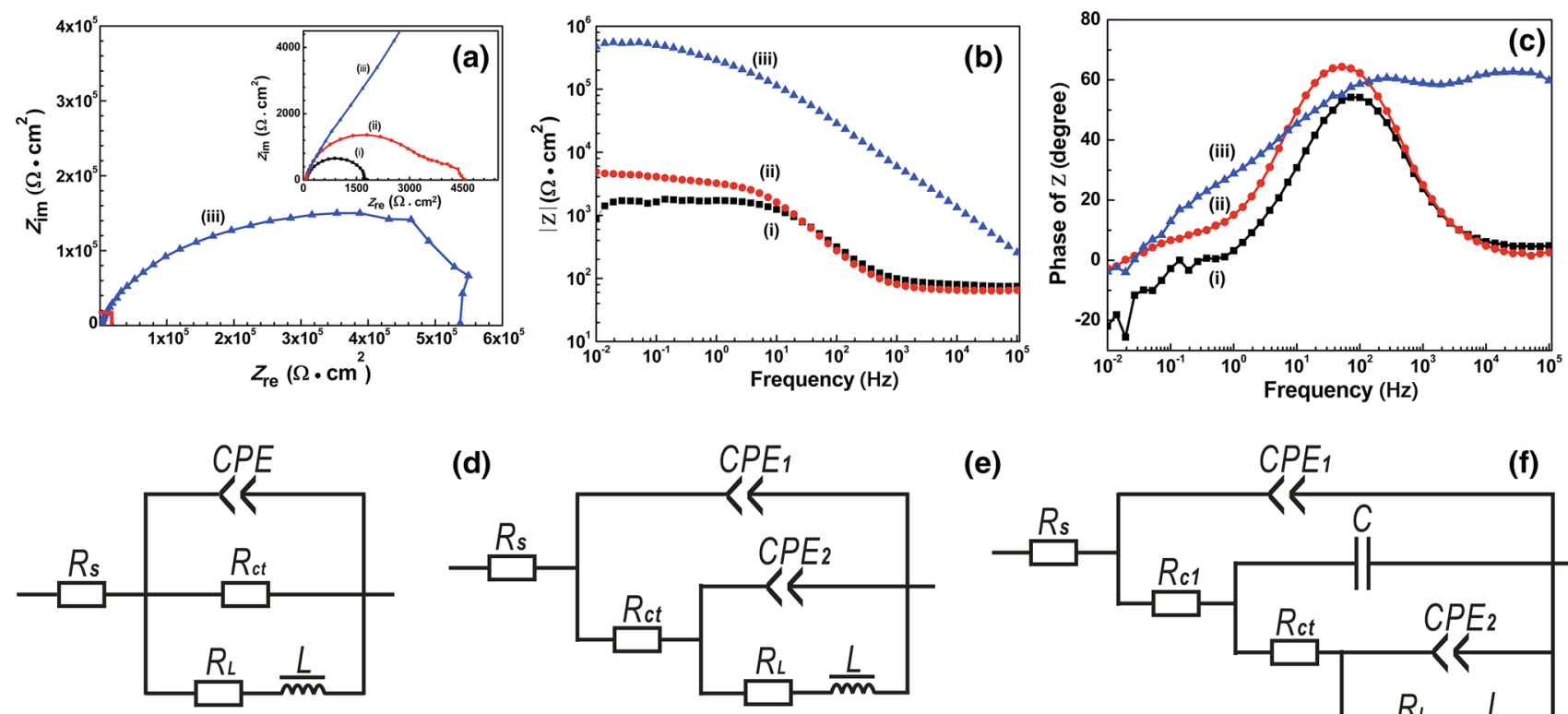

(d)

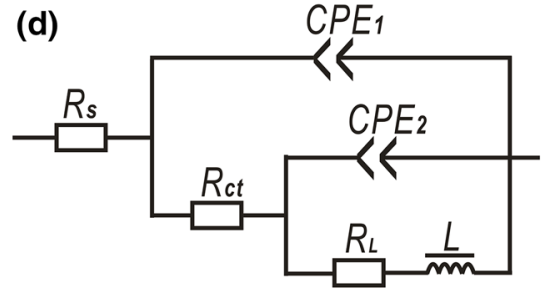

(e)

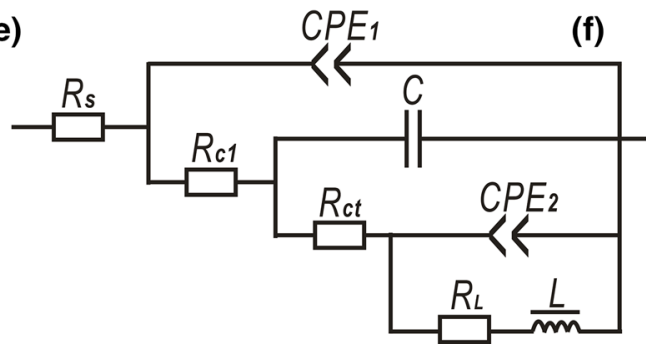

Fig. 7 a Nyquist plots and fitting curves, b Bode plots and $\mathbf{c}$ Bode plots of the phase angle versus frequency for bare AZ31 substrate $i, \mathrm{HA} / \mathrm{Mg}$ film $i i$ and PMTMS/HA film iii, and the corresponding equivalent electric circuits for EIS: d AZ31 substrate, e HA/Mg film, f PMTMS/HA film in HBSS

Table 2 Fitted electrochemical parameters of EIS after various immersion periods

\begin{tabular}{llllllllll}
\hline Sample & $R_{\mathrm{S}}\left(\Omega \mathrm{cm}^{2}\right)$ & $\begin{array}{l}Q_{1}\left(\Omega^{-1} \mathrm{~s} /\right. \\
\left.\mathrm{cm}^{2}\right)\end{array}$ & $N_{1}$ & $R_{\mathrm{c} 1}\left(\Omega \mathrm{cm}^{2}\right)$ & $Q_{2}\left(\Omega^{-1} \mathrm{~s}^{\mathrm{n}} / \mathrm{cm}^{2}\right)$ & $R_{\mathrm{ct}}\left(\Omega \mathrm{cm}^{2}\right)$ & $C\left(\mathrm{~F} / \mathrm{cm}^{2}\right)$ & $R_{\mathrm{L}}\left(\Omega \mathrm{cm}^{2}\right)$ & $L\left(\mathrm{H} \mathrm{cm}^{2}\right)$ \\
\hline AZ31 & 67.82 & $1.457 \times 10^{-5}$ & $0.86-$ & - & 852 & - & 653.4 & 647.3 \\
HA & 64.86 & $1.264 \times 10^{-5}$ & $0.88-$ & $9.32 \times 10^{-4}$ & 2826 & - & 1367 \\
PMTMS/ & 42.95 & $1.183 \times 10^{-7}$ & 0.78 & 271.82 & $2.05 \times 10^{-6}$ & 7108 & $1.42 \times 10^{-7}$ & $9.56 \times 10^{5}$ & $8.552 \times 10^{6}$ \\
HA & & & & & & & \\
\hline
\end{tabular}

follows: the PMTMS/HA coating $<$ the HA coating $<$ the AZ31 substrate. Thus, the silane hybrid HA coating possessed the best corrosion resistance in HBSS, which was in accordance with the electrochemical corrosion tests.

Figure 9 illustrates the SEM morphology and the corresponding EDS spectra of the samples immersed in the HBSS for $150 \mathrm{~h}$. First of all, some cracks could be observed on the surface of the bare AZ31 owing to the corrosion of HBSS in Fig. 9a. Secondly, for the HA film (Fig. 9b), many corrosion products had accumulated on the surface, which may be regarded as a protective barrier for the substrate. Thirdly, the PMTMS/HA film (Fig. 9c) exhibited a well-preserved surface characteristic, except for a few localized globules, which were on account of the self-polycondensation of silane [33]. The presence of the peaks of $\mathrm{Mg}, \mathrm{C}, \mathrm{O}, \mathrm{P}$ and $\mathrm{Ca}$ in the EDS spectra (Fig. 9d, e) clearly confirmed the presence of corrosion products, such as $\mathrm{Mg}(\mathrm{OH})_{2}$ and $\mathrm{Ca}-\mathrm{P}$ precipitates. At the same time, Fig. 9f also indicates that no severe attack occurred on the PMTMS/HA film after immersion through the contents of O (46.31\%), Si (24.30\%) and C.

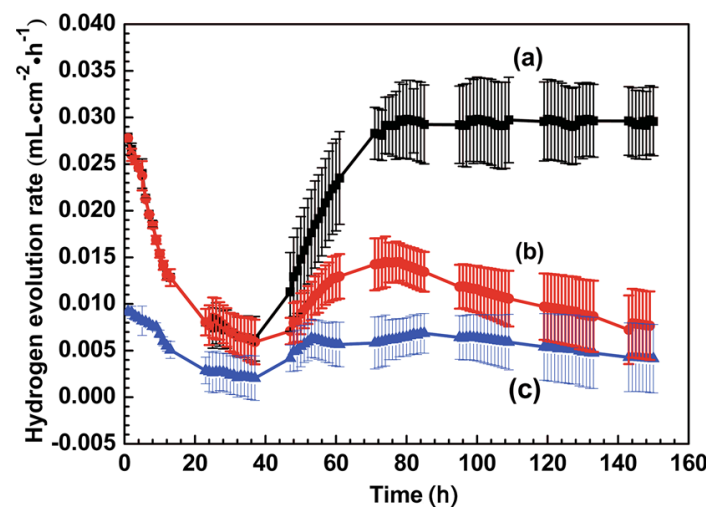

Fig. 8 HERs results of the bare AZ31 $a$, the HA film $b$ and the PMTMS/HA film $c$ in HBSS for $150 \mathrm{~h}$

The XRD spectra of AZ31, HA/AZ31 and PMTMS/HA/ AZ31 are shown in Fig. 10. Peaks corresponding to the hydroxyapatite appeared in the spectra of both HA and PMTMS/HA films, indicating that the HA coating could not be seriously corroded by the HBSS. Furthermore, also a 

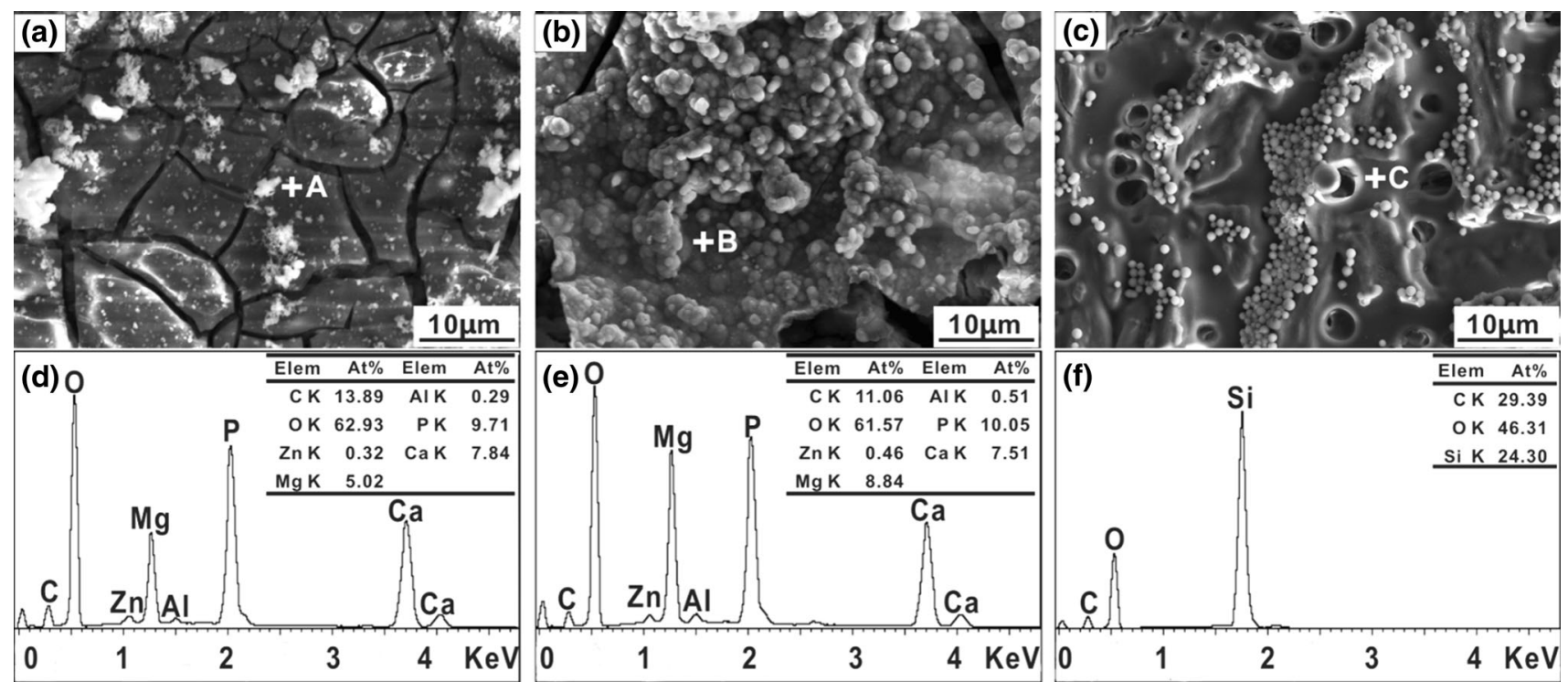

Fig. 9 Surface morphologies and the corresponding EDS spectra of the AZ31 a, d, the HA/Mg b, e and the PMTMS/HA/AZ31 c, f immersed in HBSS for $150 \mathrm{~h}$

diffraction peak of silane was detected at $22^{\circ}$ for the PMTMS/HA coating. Thus, these results indicate that the silane-modified hydroxyapatite film was relatively complete after immersion.

\subsection{Nanoscratch Testing}

The adhesion strength or the bonding force between the coating and the substrate was investigated via the nanoscratch tests, which could be used to measure the critical load $(L)$ during the adhesive failure of the coating/substrate system [34]. Figure 11 indicates the relationships between the load and the sliding distance. The critical load of the PMTMS/HA coating was $3328 \mathrm{mN}$, indicating that about $3.3 \mathrm{~N}$ (load) is needed to destroy this silane hybrid coating. At the same time, the $L_{\mathrm{HA}}$ was $2492 \mathrm{mN}$, which showed an

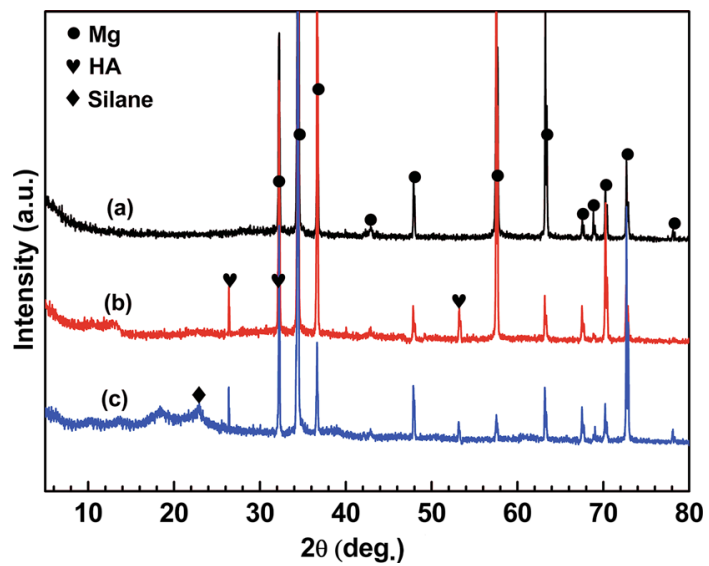

Fig. 10 XRD patterns of the AZ31 $a$, the HA/AZ31 $b$ and the PMTMS/HA/AZ31 $c$ immersed in HBSS for $150 \mathrm{~h}$ excellent adhesion of the HA coating with the AZ31 magnesium alloy. Thus, the results demonstrated that the silane could further enhance the adhesion strength in the PMTMS/HA-coated AZ31.

\section{Discussion}

\subsection{Formation of the Silane Hybrid Coating}

According to the elemental compositions of $\mathrm{Ca}, \mathrm{P}, \mathrm{C}$ and $\mathrm{O}$ in the EDS analysis (Fig. 4c) and the presence of $\mathrm{PO}_{4}{ }^{3-}$ and $\mathrm{OH}^{-}$groups in the FTIR patterns (Fig. 3a), the

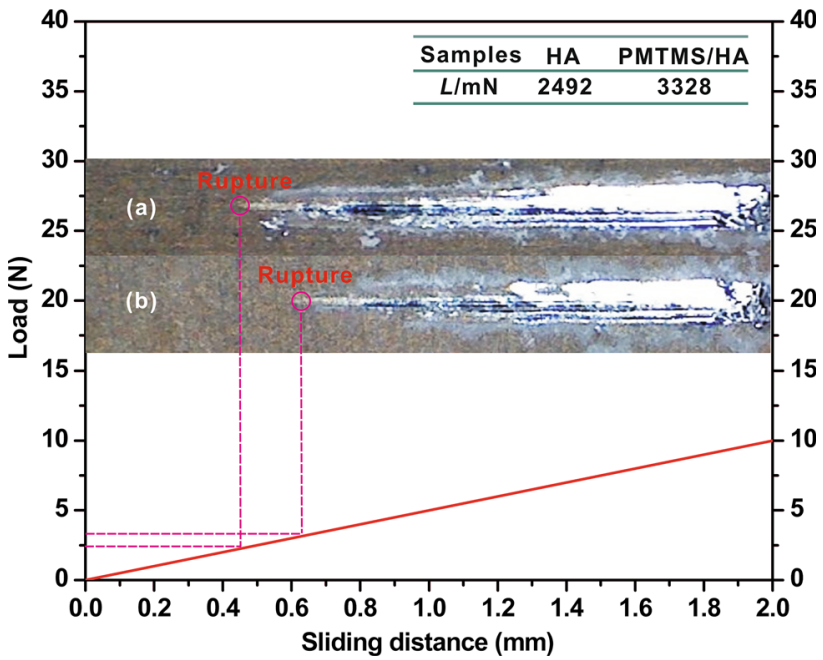

Fig. 11 Nanoscratch test results of the HA and the PMTMS/HA coating 
formation of the hydroxyapatite coating could be clearly confirmed. During the hydrothermal treatment, the $\mathrm{OH}^{-}$ firstly reacted with the dihydrogen phosphate $\left(\mathrm{H}_{2} \mathrm{PO}_{4}{ }^{-}\right)$, thereby yielding the hydrogen phosphate $\left(\mathrm{HPO}_{4}{ }^{2-}\right)$. Then, the $\mathrm{HPO}_{4}{ }^{2-}$ would combine with $\mathrm{Ca}^{2+}$ to form the $\mathrm{CaHPO}_{4}$. This reaction sequence is represented in reactions (1) and (2):

$$
\begin{aligned}
& \mathrm{H}_{2} \mathrm{PO}_{4}^{-}+\mathrm{OH}^{-} \rightarrow \mathrm{HPO}_{4}^{2-}+\mathrm{H}_{2} \mathrm{O}, \\
& \mathrm{HPO}_{4}^{2-}+\mathrm{Ca}^{2+} \rightarrow \mathrm{CaHPO}_{4} .
\end{aligned}
$$

At the same time, the $\mathrm{HPO}_{4}{ }^{2-}$ could also react with $\mathrm{OH}^{-}$to generate the phosphate $\left(\mathrm{PO}_{4}{ }^{3-}\right)$, which would then react with the $\mathrm{Ca}^{2+}$ to form the $\mathrm{Ca}_{3}\left(\mathrm{PO}_{4}\right)_{2}$ according to reactions (3) and (4):

$$
\begin{aligned}
& \mathrm{HPO}_{4}^{2-}+\mathrm{OH}^{-} \rightarrow \mathrm{PO}_{4}^{3-}+\mathrm{H}_{2} \mathrm{O}, \\
& 2 \mathrm{PO}_{4}^{3-}+3 \mathrm{Ca}^{2+} \rightarrow \mathrm{Ca}_{3}\left(\mathrm{PO}_{4}\right)_{2} .
\end{aligned}
$$

It is noted that peaks of $\mathrm{CaHPO}_{4}$ and $\mathrm{Ca}_{3}\left(\mathrm{PO}_{4}\right)_{2}$ were both absent from the XRD patterns. Thus, probably the $\mathrm{HPO}_{4}{ }^{2-}$ and the $\mathrm{PO}_{4}{ }^{3-}$ were transformed into hydroxyapatite as shown in reactions (5) and (6):

$$
\begin{aligned}
& 10 \mathrm{Ca}^{2+}+10 \mathrm{HPO}^{2-}+12 \mathrm{OH}^{-} \\
& \quad \rightarrow \mathrm{Ca}_{10}\left(\mathrm{PO}_{4}\right)_{6}(\mathrm{OH})_{2}+10 \mathrm{H}_{2} \mathrm{O}+4 \mathrm{PO}_{4}^{3-}, \\
& 10 \mathrm{Ca}^{2+}+6 \mathrm{PO}_{4}^{3-}+2 \mathrm{OH}^{-} \rightarrow \mathrm{Ca}_{10}\left(\mathrm{PO}_{4}\right)_{6}(\mathrm{OH})_{2} .
\end{aligned}
$$

Similarly, the formation of the silane-HA hybrid coating was clearly demonstrated through the content of $\mathrm{Si}, \mathrm{O}$ and $\mathrm{C}$ in the EDS (Fig. 4f) as well as by the appearance of the $\mathrm{Si}-\mathrm{C}$ groups, the $\mathrm{Si}-\mathrm{O}-\mathrm{C}$ band, the $\mathrm{Si}-\mathrm{O}-\mathrm{Si}$ chain and the $\mathrm{Si}-\mathrm{OH}$ band in the FTIR patterns (Fig. 3b). The PMTMS was prepared by methyltrimethoxysilane (MTMS) as follows:

$\mathrm{CH}_{3}-\mathrm{Si}-(\mathrm{R}-\mathrm{O})_{3}+3 \mathrm{H}_{2} \mathrm{O} \rightarrow \mathrm{CH}_{3}-\mathrm{Si}-(\mathrm{OH})_{3}+3 \mathrm{R}-\mathrm{OH}$

Then, the $\mathrm{CH}_{3}-\mathrm{Si}-(\mathrm{OH})_{3}$ would cross-link the $\mathrm{Ca}_{10}\left(\mathrm{PO}_{4}\right)_{6}(\mathrm{OH})_{2}$ by hydrolysis condensation reactions to form the $\mathrm{Si}-\mathrm{O}-\mathrm{Si}$ groups.

\subsection{Corrosion Mechanism}

The corrosion mechanism of the PMTMS/HA coating could be confirmed via the HER test, plus the SEM, the EDS and the XRD analyses. Firstly, the silane completely covered the surface of the HA coating, which effectively blocked the penetration of HBSS. Then, the silane underwent a self-polycondensation because of the swelling of the PMTMS, forming many globules. Secondly, with the expansion of the silane, the hydroxyapatite film was exposed to the HBSS in some areas, which may be considered as a barrier for the substrate. Finally, the HA film was destroyed, and then, the newly unprotected AZ31 was corroded by the HBSS following reactions (8), (9) and (10):

$\mathrm{Mg} \rightarrow \mathrm{Mg}^{2+}+2 \mathrm{e}^{-}$,

$2 \mathrm{H}_{2} \mathrm{O}+2 \mathrm{e}^{-} \rightarrow 2 \mathrm{OH}^{-}+\mathrm{H}_{2} \uparrow$,

$\mathrm{Mg}+2 \mathrm{H}_{2} \mathrm{O} \rightarrow \mathrm{Mg}(\mathrm{OH})_{2}+\mathrm{H}_{2} \uparrow$.

\section{Conclusions}

1. A silane hybrid HA coating was successfully fabricated via hydrothermal treatment and silane crosslinking method with the enhanced anti-corrosion performance.

2. The electrochemical tests demonstrated that the PMTMS/HA film had the lowest $I_{\text {corr }}$ $\left(3.86 \times 10^{-8} \mathrm{~A} / \mathrm{cm}^{2}\right)$ of all the samples.

3. The PMTMS/HA coating had the lowest $\mathrm{H}_{2}$ evolution rate during the immersion tests.

4. Owing to the physical and chemical stabilities, the combination of HA and silane resulted in a significant improvement in the corrosion resistance of magnesium alloys.

Acknowledgements This work was supported by the National Natural Science Foundation of China (No. 51571134) and the Shandong University of Science and Technology (SDUST) Research Fund (No. 2014TDJH104).

\section{References}

[1] M. Razavi, M. Fathi, O. Savabi, D. Vashaee, L. Tayebi, J. Mater. Sci.-Mater. Med. 26, 184 (2015)

[2] P. Wan, L.L. Tan, K. Yang, J. Mater. Sci. Technol. 32, 827 (2016)

[3] J.E. Gray-Munro, C. Seguin, M. Strong, J. Biomed. Mater. Res. A 91, 221 (2009)

[4] X. Chen, M. Zhang, X. Pu, G. Yin, X. Liao, Z. Huang, Y. Yao, Surf. Coat. Technol. 249, 97 (2014)

[5] L. Wang, Q. Zong, W. Sun, Z. Yang, G. Liu, Corros. Sci. 93, $256(2015)$

[6] L. Cui, R.C. Zeng, S. Li, F. Zhang, E.H. Han, RSC Adv. 6, 63107 (2016)

[7] A. Arifin, A.B. Sulong, N. Muhamad, J. Syarif, M.I. Ramli, Mater. Design. 6, 55 (2014)

[8] S.K.F. Asl, S. Nemeth, M.J. Tan, Surf. Coat. Technol. 270, 197 (2015)

[9] S.V. Gnedenkov, S.L. Sinebryukhov, A.G. Zavidnaya, V.S. Egorkin, A.V. Puz, D.V. Mashtalyar, V.I. Sergienko, A.L. Yerokhin, A. Matthews, J. Taiwan Inst. Chem. E 45, 3104 (2014)

[10] S.R. Kunst, M. Longhi, E.K.K. Baldin, R. Boniatti, L.V.R Beltrami, C.D.F. Malfatti, J. Mater. Eng. Perform. 229, 1 (2016)

[11] F. Lampert, A.H. Jensen, R.U. Din, P. Møller, Surf. Coat. Technol. 307, 879 (2016)

[12] Y. Liu, J. Liu, Constr. Build. Mater. 122, 90 (2016) 
[13] C. Miliani, M.L. Velo-Simpson, G.W. Scherer, J. Cult. Herit. 8, 1 (2007)

[14] X. Liu, Z. Yue, T. Romeo, J. Weber, T. Scheuermann, S. Moulton, G. Wallace, Acta Biomater. 9, 8671 (2013)

[15] H. Lin, C. Zhao, W. Ma, K. Shao, H. Li, Y. Zhang, N. Hui, J. Power Sources 195, 762 (2010)

[16] L. Liu, P. Li, Y. Zou, K. Luo, F. Zhang, R.C. Zeng, S. Li, Surf. Coat. Technol. 291, 7 (2016)

[17] S. Hiromoto, M. Tomozawa, Mater. Trans. 51, 2080 (2010)

[18] V.O. Kollath, Q. Chen, R. Closset, J. Luyten, K. Traina, S. Mullens, A.R. Boccaccini, R. Cloots, J. Eur. Ceram. Soc. 33, 2715 (2013)

[19] D. Cai, W. Liu, R. Li, W. Zhang, Y. Mei, J. Mater. Sci. 39, 719 (2004)

[20] Q. Fu, L. Chen, K. Liu, F. Chen, Express Polym. Lett. 6, 629 (2012)

[21] Y. Xiong, C. Lu, C. Wang, R.G. Song, J. Biobased Mater. Bioenergy 8, 158 (2014)

[22] H. Tang, D. Yu, Y. Luo, F. Wang, Appl. Surf. Sci. 264, 816 (2013)

[23] Q. Yuan, J. Wu, C. Qin, A. Xu, Z. Zhang, S. Lin, X. Ren, P. Zhang, Surf. Coat. Technol. 307, 461 (2016)

[24] B. Li, Y. Chen, W. Huang, W. Yang, X. Yin, Y. Liu, Ceram. Int. 42, 13074 (2016)
[25] V.Q. Dang, P.B. Sarawade, A. Hilonga, J.K. Kim, Y.G. Chai, H.K. Sang, J.Y. Ryu, H.T. Kim, Colloid Surf. A 389, 118 (2011)

[26] Y.G. Zhao, H.Y. Shen, J.W. Shi, X.H. Chen, M.C. Jin, J. Chromatogr. A 1218, 5568 (2011)

[27] L. Calabrese, L. Bonaccorsi, E. Proverbio, J. Coat. Technol. Res. 9, 597 (2012)

[28] S. Rakmae, Y. Ruksakulpiwat, W. Sutapun, N. Suppakarn, Mater. Sci. Eng. C Mater. 32, 1428 (2012)

[29] W. Fortuniak, J. Chojnowski, S. Slomkowski, A. NyczykMalinowska, P. Pospiech, U. Mizerska, Mater. Chem. Phys. 155, 83 (2015)

[30] S.A. Mahadik, M.S. Kavale, S.K. Mukherjee, A.V. Rao, Appl. Surf. Sci. 257, $333(2010)$

[31] A. Zomorodian, M.P. Garcia, E.S.T. Moura, J.C. Fernandes, M.H. Fernandes, M.F. Montemor, Acta Biomater. 9, 8660 (2013)

[32] W.G. Chi, S.G. Wu, Experimental Petroleum Geology 22, 131 (2000). (in Chinese)

[33] L. Yang, J. Feng, W. Zhang, J.E. Qu, Appl. Surf. Sci. 256, 6787 (2010)

[34] Z.L. Wang, R.C. Zeng, Trans. Nonferrous Met. Soc. 20, 665 (2010) 